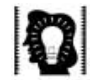

special articles
Services and Support for Older People with Mental Health Problems: Second Report. Age Concern England, 2007.

7 Layard R, Clark D, Knapp M, Mayraz $\mathrm{G}$. Cost benefit analysis of psychological therapy. Natl Inst Econ Rev 2007; 202: 90-8.

8 Appleby L. Mental HealthTen Years On: Progress on Mental Health Care Reform. Department of Health, 2007.

9 Philp I, Appleby L. Securing Better Mental Health for Older Adults. Department of Health, 2005.
10 Phillips C, Thompson G. What is a QALY? Hayward Medical Communications, 2001 (http:// www.jr2.ox.ac.uk/bandolier/ painres/download/whatis/ QALY.pdf).

11 Rosser RM, WattsVC. The measurement of hospital output. Int J Epidemio/ 1972; 1: 361-8.

12 Bosanquet N, Rawlins M. Qualityadjusted life years are too rigid for the NHS. Health ServJ 2005; 115 20-1.

13 Royal College of Psychiatrists Response from the Faculty of Old Age Psychiatry to the NICE Appraisal Consultation Document:
Donepezil, Rivastigmine, Galantamine and Memantine for the Treatment of Alzheimer's Disease. Royal College of Psychiatrists, 2005 (http:// www.rcpsych.ac.uk/pdf/ responseNICE_March05.pdf).

14 House of Lords and House of Commons Joint Committee on Human Rights. The Human Rights of Older People in Healthcare (vol. 1). TSO (The Stationery Office), 2007.
15 British and Irish Legal Information institute (BAILII). England and Wales Database. BAILII, 2008.

16 House of Lords and House of Commons Joint Committee on Human Rights. Government Response to the Committee's Eighteenth Report of Session 2006-07: The Human Rights of Older People in Healthcare. TSO (The Stationery Office), 2007.

\title{
Improving access to psychological therapies for all adults
}

\author{
SUMMARY \\ New psychological services are \\ about to roll out across England. \\ The National Institute for Health \\ and Clinical Excellence clinical \\ guidelines have led to government \\ investment in the Improving Access \\ to Psychological Therapies (IAPT) \\ programme. New IAPT services
}

\author{
should cut waiting times for \\ psychological treatment of \\ depression and anxiety disorders \\ from months to days. They are \\ intended to be available for all adults \\ on the basis of need rather than age. \\ It is not currently illegal for patients \\ to be discriminated against by the \\ National Health Service (NHS)
}

\begin{abstract}
because of their age. The government intends to introduce new legislation against age discrimination in the provision of goods, facilities and services by the NHS. Further investment and service development will be needed to counter existing agerelated inequalities in mental health services
\end{abstract}

No legislation currently protects people from age discrimination in the provision of goods, facilities and services by the National Health Service (NHS). ${ }^{1}$ Increasing evidence of inequality in English mental health service provision between 'younger adults' and people over 65 years old has been reported, with lower use of services by older people with depression and anxiety disorders. ${ }^{2}$ Newly formed mental health teams have provided services for adults of working age, excluding older adults. For example, a survey of English crisis resolution teams found that less than a third of mental health trusts provided the same service to older and younger adults and only one in six areas frequently provided crisis services to older people. ${ }^{3}$ Investment in psychological services for older people has been called a 'national disgrace' ${ }^{4}$ and recommended psychological therapies are reported to be almost totally unavailable for older adults. ${ }^{5}$ In contrast, the Improving Access to Psychological Therapies (IAPT) programme has recently been described as 'one of the most important advances for NHS services in a generation. ${ }^{6}$ What is IAPT and will older adults benefit?

\footnotetext{
† See special article, pp. 184-185
} this issue.

\section{IAPT pilots and pathfinders}

Around the country, NHS psychological therapies have been either unavailable or subject to significant delays resulting in massive undertreatment of depression and anxiety disorders. ${ }^{7}$ The 2006 Depression Report argued that NHS evidence-based psychological therapies should be available for all who need them and the most important benefit of government investment in psychological services would be the reduction in distress and suffering. It stated that investment would more than pay for itself through savings on other NHS services, fewer state benefits, and with more people working. ${ }^{8}$

In 2006, two IAPT pilot projects began testing the effectiveness of developing evidence-based psychological interventions in primary and community settings (www.mhchoice.csip.org.uk/psychological-therapies / psychological-therapies.html). The core purpose of these demonstration sites was to collect evidence to develop a business case for national roll out of the IAPT service model. ${ }^{9}$ Although the pilots were reported to have achieved impressive outcomes, ${ }^{10}$ they were criticised for only providing their services to people of 'working age', despite older people's ability to benefit from psychological therapies. Age Concern cited institutionalised age discrimination in mental health services. ${ }^{11}$

These criticisms appear to have been addressed in 2007 with 11 new 'Pathfinder' sites extending the scope of IAPT to support the case for further service expansion. A mandatory feature for all Pathfinder sites was the availability of services to people of all ages on the basis of 
need. ${ }^{12}$ Effort was focused on the specific needs of older people and other vulnerable groups while developing pathways to meet the needs of the whole population. ${ }^{7}$ This signalled a shift from services only targeting working-age adults. The IAPT programme routinely collects data on patient age, gender, ethnicity, disability and sexual orientation and no evidence has been found to suggest that the roll-out of the IAPT programme has created any specific inequalities. Special interest groups have been set up to review access issues and care pathways to ensure inequalities do not occur for older people. ${ }^{13}$ The Department of Health has emphasised that primary care trust commissioners must take steps to eliminate discrimination and promote equality of opportunity to offer psychological intervention to everyone who will benefit. ${ }^{14}$

\section{The future of IAPT}

In October 2007, the government announced a 3-year programme of increasing funding for IAPT. ${ }^{15}$ By 2010/11 the NHS will be spending $\mathrm{f} 170$ million per year of new money on expanding psychological therapies, to enable the NHS in England to implement National Institute for Health and Clinical Excellence (NICE) guidelines for people diagnosed with depression and anxiety disorders. ${ }^{14}$ The aim is for the money to be used to train 3600 extra therapists over 3 years to treat 900000 more people. The government also predicts 25000 fewer people with mental health problems will receive sick pay or benefits and all general practitioner practices will have access to psychological therapies, with average waiting time down from 18 months to a few weeks. ${ }^{10}$

People who are referred or present themselves to a new IAPT service will be assessed by a member of the psychological therapies team and then offered NICErecommended treatment in primary care or community setting. For example, a stepped care system is recommended for depression. Individuals with mild to moderate severity illness will receive 'low intensity' treatment: watchful waiting computerised cognitive-behavioural therapy (CBT), guided self-help or up to seven sessions of face-to-face intervention. Non-responders or those with more severe depression receive up to 20 sessions of 'high

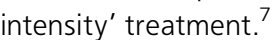

\section{IAPT and older people}

Government policy states that need, not age, should determine access to psychological therapies. ${ }^{16}$ Recent NICE commissioning guidance for the new psychological services outlines that they should be available for adults of all ages. It defines adults as people aged 15 or above and suggests a benchmark rate of CBT referrals of $3 \%$ of adults per year. The National Institute for Health and Clinical Excellence highlights the responsibility of commissioners and providers to implement guidance to meet local needs. ${ }^{17}$

In June 2008 it was announced that 32 primary care trusts had been selected to roll out the next stage of
IAPT around the country. ${ }^{6}$ To be selected, primary care trusts needed to carry out an accurate assessment of health need in relation to prevalence of depression and anxiety and of the gaps between existing provision and unmet need. A local equality impact assessment was also required, to demonstrate that services would eliminate discrimination. ${ }^{7}$ If guidance is implemented correctly, older people will benefit from the increased investment in IAPT. Senior professionals from specialist health and social care services have a key role in advocating for older people in future service development. ${ }^{18}$

\section{Age discrimination and the equality bill}

The government plans to make it illegal to discriminate against someone because of their age when providing health and social services in a new equality bill. ${ }^{19}$ The new legislation will ban unjustifiable age discrimination against people over 18. The Department of Health recently commissioned studies looking at the costs and benefits of eliminating age discrimination. ${ }^{20}$ Concerns have been raised that the use of quality adjusted life years (QALYS) by NICE to assess the cost-effectiveness of treatments may be age-discriminatory. ${ }^{21}$ However, a recent review of the theoretical literature on cost-effectiveness analysis indicates that many of the age-based criticisms made against cost-effectiveness analysis do not refer to its application in the NHS. The main issue relates to whether treating older people produces fewer QALYs, but costeffectiveness analysis is typically assessed across all age groups, and so it is unlikely to produce direct age discrimination. The review does not recommend any changes and suggests that NICE currently adopts a pragmatic approach which involves a lower potential for agebased rationing than other options. Relatively few modifications to the current system appear to be feasible, practical and possible without further research. Alternatives to QALYS were deemed more ageist or assumed healthcare is a right, regardless of affordability. ${ }^{1}$

\section{Conclusions}

The government hopes IAPT will deliver new, state-ofthe-art psychological therapy services to raise standards of recognition and treatment for adults who are diagnosed with depression and anxiety disorders. ${ }^{9}$ The current regime seems to be trying to both improve the provision of evidence-based NHS services and reduce healthcare inequalities, by increasing NHS investment and developing anti-discrimination law. Since 1999, the Labour government has increased the annual investment in specialist mental health services by over $£ 1.5$ billion. ${ }^{22}$ A recent study estimated that increasing service provision for adults with a mental health problem aged over 55 to the level received by middle-aged individuals (35-54 years), would cost an additional $f 2$ billion a year at 2006/ 7 prices. ${ }^{2}$ Will the next government continue to focus on increasing investment and improving equality in public services? 


\section{Declaration of interest}

None.

special articles

\section{References}

1 Edlin R, RoundJ, McCabe C, Sculpher M, Claxton K, Cookson R. Cost-Effectiveness Analysis and Ageism: a Review of theTheoretica Literature. Leeds Institute of Health Sciences, 2008 (http:// www.leeds.ac.uk/lihs/auhe/ papers/cea_ageism.pdf).

2 BeechamJ, Knapp M, FernándezJ-L, Huxley P, Mangalore R, McCrone P, et al. Age Discrimination in Mental Health Services. Personal Social Services Research Unit, 2008 (http://www.pssru.ac.uk/pdf/ dp2536.pdf).

3 Cooper C, Regan C, TandyAR, Johnson S, Livingston G. Acute mental health care for older people by crisis resolution teams in England. Int J Geriatr Psychiatry 2007; 22: 263-5.

4 Anderson D, Banks R, Chew-Graham C, Crome P, Kingston $\mathrm{P}$, le Mesurier $\mathrm{N}$, et a A Collective Responsibility to Act Now on Ageing and Mental Health. A Consensus Statement Care Services Improvement Partnership (http://www. olderpeoplesmentalhealth. csip.org.uk/silo/files/consensusstatement-august.pdf).

5 Royal College of Psychiatrists \& Royal College of General Practitioners. Psychological Therapies in Psychiatry and Primary
Care (CR151). Royal College of Psychatrists, 2008.

6 Department of Health. 32 PCTs to Spearhead Surge in Talking Therapies. News Distribution Service for Government and the Public Sector, 2008 (http:// nds.coi.gov.uk/Content/ Detail.asp? ReleaselD = 370515\&NewsArealD = 2).

7 Department of Health. Improving Access to Psychological Therapies Implementation Plan: National Guidelines for Regional Delivery. Department of Health, 2008.

8 The Centre for Economic Performance's Mental Health Policy Group. The Depression Report: a New Deal for Depression and Anxiety Disorders. London School of Economics, 2006 (http://cep.|se.ac.uk/textonly/ research/mentalhealth/ DEPRESSION_REPORT_LAYARD.pdf).

9 Department of Health. Improving Access toPsychological Therapies Specification for the Commissioner-Led Pathfinder Programme. Department of Health, 2007.

10 Department of Health. Johnson announces $\mathrm{f} 170$ million boost to mental health therapies. News Distribution Service for Government and the Public Sector, 2007 (http://www.gnn.gov.uk/
content/detail.asp?ReleaselD = 321341\&NewsArealD = 2\&Nav).

11 Age Concern. Age of Equality? Outlawing Age Discrimination Beyond the Workplace. Age Concern England, 2007 (http:// www.ageconcern.org.uk/ AgeConcern/Documents/ ACE_DLR_report_FINAL_PDF.pdf).

12 Care Services Improvement Partnership. IAPT Outline Service Specification. CSIP, 2007 (http:// www.mhchoice.csip.org.uk/ silo/files/outline-servicespecification.pdf).

3 Department of Health. Improving Access to Psychological Therapies Implementation Plan: Equality mpact Assessment. Department of Health, 2008

14 Department of Health. Improving Access to Psychological Therapies Commissioning Toolkit. Department of Health, 2008

15 Directgov. Comprehensive spending review 2007. Directgov, 9 October 2007 (http:// www.direct.gov.uk/en/N11/ Newsroom/DG_070872).

16 Department of Health \& Care Services Improvement Partnership. Everybody's Business. integrated Mental Health Service for OlderAdults: a Service Development Guide. Department of Health, 2005 (http:// kc.csip.org.uk/upload/ everybodysbusiness.pdf).

17 National Institute for Health and Clinical Excellence. Determining local service levels for a service providing cognitive behavioural therapy for the management of common mental health problems. NICE, 2007.

18 Philp I, Appleby L. Securing Better Mental Health for Older Adults. Department of Health, 2005.

19 Government Equalities Office. Framework for a Fairer Future - The Equality Bill. TSO (The Stationery Office), 2008.

20 Department of Health. Research on Eliminating Age Discrimination in Social Services and Mental Health Services. Department of Health, 2008.

21 Centre for Policy on Ageing. A Literature Review of the Likely Costs and Benefits of Legislation to Prohibit Age Discrimination in Health, Social Care and Mental Health Services and Definitions of Age Discrimination that Might Be Operationalised for Measurement. CPA, 2007 (http://www.cpa.org.uk/ information/reviews/ CPA-age_discrimination costs_report.pdf).

22 Appleby L. Mental HealthTen Years On: Progress on Mental Health Care Reform. Department of Health, 2007.

Pradip Ghosh Specialist Registrar, West London Mental Health Trust, John ConollyWing, St Bernard's Hospital, Uxbridge Road, Southall, Middlesex UB1 3EU, email: Pradip.Ghosh@wlmht.nhs.net 